\title{
EFEKTIFITAS PENGGUNAAN MEDIA ZOOM TERHADAP PEMBELAJARAN PADA MASA PANDEMI COVID-19
}

\author{
Zulfikar \\ Fakultas Psikologi, Universitas Indonesia Timur Makassar \\ Email : zulfikarmikom@gmail.com
}

\begin{abstract}
Online learning is a learning method that is currently being actively developed by every teacher and educator. This learning method is a solution for the limited learning activities during the Covid 19 pandemic as it is today. Online learning is considered to be able to make learning activities more efficient and effective, although it cannot be categorized as low cost, but online learning can save operational costs for educational institutions. The effectiveness of distance learning rests on the ability of each teacher to deliver teaching material like a face-to-face learning process. In addition, the material or learning content presented by educators must be packaged in language that is easy to understand so that each student is able to understand the material presented properly. The distance learning model for elementary school students is presented as much as possible in the interactivity between educators and students as preferred by elementary school students. Currently, there are many applications that provide video conferencing facilities to help the learning process so that between educators and students can still carry out face-to-face even though they are in different places. The application or media that is currently widely used by schools is the Zoom application. The Zoom application has many advantages when compared to various similar applications, so it is very suitable as a choice oflearning media during the Covid-19 pandemic. Research on the effectiveness of using zoom media for learning in the midst of the Covid-19 pandemic will be carried out at SDN 117 Leppangeng to measure the effectiveness of the media for learning amid the Covid-19 pandemic. This research uses a qualitative approach.
\end{abstract}

Keyword : Zoom, learning, Covid-19 pandemic

\begin{abstract}
ABSTRAK
Pembelajaran melalui daring merupakan metode pembelajaran yang saat ini aktif dikembangkan oleh setiap tenaga pengajar dan pendidik. Metode pembelajaran ini menjadi sebuah solusi bagi terbatasnya kegiatan pembelajaran dimasa pandemi Covid 19 seperti saat ini. Pembelajaran daring dinilai dapat mengefisienkan dan mengefektifkan kegiatan pembelajaran, meskipun tidak dapat dikategorikan berbiaya murah namun pembelajaran daring ini tergolong dapat menghemat biaya operasional lembaga pendidikan. Efektifitas pembelajaran jarak jauh bertumpu pada kemampuan setiap tenaga pengajar dalam menyampaikan materi pengajaran layaknya proses pembelajaran tatap muka. Disamping itu, materi atau isi pembelajaran yang disajikan oleh pendidik harus dikemas dengan bahasa yang mudah dimengerti agar setiap siswa mampu memahami materi yang disampaikan dengan baik. Model pembelajaran jarak jauh bagi siswa sekolah dasar sebisa mungkin disajikan secara interaktifitas antara pendidik dan peserta didik sebagaimana yang disukai oleh siswa sekolah dasar. Saat ini telah banyak tersedia aplikasi yang menyediakan fasilitas video conference untuk membantu proses pembelajaran sehingga antara pendidik dan siswa tetap dapat
\end{abstract}


melaksanakan tatap muka meskipun berada ditempat yang berbeda. Aplikasi atau media yang saat ini banyak digunakan oleh sekolah adalah aplikasi Zoom. Aplikasi Zoom memiliki banyak kelebihan apabila dibandingkan dengan berbagai aplikasi yang serupa sehingga sangat pantas untuk dijadikan pilihan media pembelajaran di masa pandemi covid-19. Penelitian mengenai efektifitas penggunaan media zoom terhadap pembelajaran di tengah pandemic covid-19 ini akan dilaksanakan di SDN 117 Leppangeng guna mengukur keefektifan media tersebut terhadap pembelajaran di tengah pandemic covid-19 ini. Penelitian ini menggunakan pendekatan kualitatif.

Keyword : Zoom, pembelajaran, pandemi Covid-19

\section{PENDAHULUAN}

Wabah Covid-19 merupakan sebuah pandemi yang tidak hanya mempengaruhi aspek pendidikan numun juga seluruh aspek kehidupan masyarakat di dunia khususnya di Indonesia. Situasi ini telah menjadi sebuah tantangan tersendiri hagi seluruh lembaga pendidikan, termasuk lembaga Pendidikan Sekolah Dasar. Melalui Kementerian Pendidikan dan Kebudayaan guna menyikapi hal ini, Pemerintah telah mengeluarkan larangan bagi seluruh jenjang pendidikan untuk melaksanakan pembelajaran tatap muka langsung dalam ruang kelas dan menghimbau setiap sekolah untuk melaksanakan pembelajaran secara on line atau daring. Dalam situasi yang tak terduga ini, kondisi telah memaksa seluruh elemen pendidikan termasuk guru kelas untuk berpikir bagaimana mengubah dan menyiapkan proses belajar bagi siswa dimana sebelumnya masih menggunakan metode tatap muka menjadi model pembelajaran daring yang diselenggarakan di rumah masing-masing. Guru sebagai pendidik tentunya diharapkan mampu menemukan solusi terbaik untuk proses pembelajaran daring yang tepat atau sesuai dengan kebutuhan dan kemampuan siswa.

Metode pembelajaran daring merupakan cara pembelajaran yang memanfaatkan akses internet dengan menawarkan berbagai keunggulan yang meliputi aksebilitas, konektivitas, fleksibilitas dan kemampuan untuk memuncul kan berbagai jenis interaksi pembelajaran. Sistem pembelajaran berbasis interniet atau pembelajaran daring ini juga bertumpu pada adanya dukungan perangkat mobile, seperti handphone berkategori smartphone, laptop atau komputer untuk dapat mengakses aplikasi kapan saja dan dimana saja (Gikas dan Grant, 2 013). Di samping itu, pembelajaran daring juga memerlukan media aplikasi sebagai sarana untuk melaksanakan kegiatan pembelajaran di antaranya google classroom, zoom meeting, whatsapp dan google meet.

Dengan keunggulan fleksibitas yang tinggi, pembelajaran jarak jauh dapat mempersingkat waktu pembelajaran serta menghemat biaya opersional lembaga pendidikan (Silahuddin, 2015). Efektifitas pembelajaran jarak jauh bertumpu pada kemampuan setiap tenaga pengajar dalam menyampaikan materi pengajaran layaknya proses pembelajaran tatap muka. Disamping itu, materi atau isi pembelajaran yang disajikan oleh pendidik harus dikemas dengan bahasa yang mudah dimengerti agar setiap siswa mampu memahami materi yang disampaikan dengan baik. Model pembelajaran jarak jauh bagi siswa sekolah dasar sebisa mungkin disajikan secara interaktifitas antara pendidik dan peserta didik sebagaimana yang disukai oleh siswa sekolah dasar. Saat ini telah banyak tersedia aplikasi yang menyediakan fasilitas video 
conference untuk membantu proses pembelajaran sehingga antara pendidik dan siswa tetap dapat melaksanakan tatap muka meskipun berada ditempat yang berbeda (Sandiwarno, 2016).

Orang tua berperan penting dalam proses belajar siswa di rumah. Pembelajaran jarak jauh ini secara tidak langsung mewajibkan para orang tua untuk menggunakan teknologi seperti smartphhone atau perangkat lain yang dapat mengakses jaringan internet. Untuk mengikutkan anak mereka dalam sistem pembelajaran ini, setiap orang tua setidaknya menyiapkan satu alat atau sistem pembelajaran jarak jauh serta melakukan bimbingan pada anak mereka agar bisa secara mandiri menggunakan teknologi dalam pembelajaran tersebut untuk meningkatkan kualitas pembelajaran anak dan tentunya selalu dibawah pengawasan mereka. Dalam penggunakan teknologi pembelajaran setiap orang tua harus turut menguasai teknologi tersebut sebagai fungi pengawasan dan pembimbingan agar pembelajaran dapat terlaksana dengan baik.

Melalui observasi awal yang dilakukan di Sekolah Dasar Negeri (SDN) 117 Leppangeng Bone, diperoleh kesimpulan bahwa sarana pembelajaran yang digunakan oleh sekolah tersebut adalah aplikasi zoom meeting. Penerapan aplikasi zoom meeting pada awalnya menjadi sebuah masalah bagi guru, siswa dan orang tua siswa karena sebagian besar guru, orang tua dan juga siswa belum terbiasa menggunakan media pembelajaran daring tersebut terutama terkait teknis operasionalisasi menggunakan model program zoom meeting, kesulitan untuk mengakses jaringan dan masih banyak siswa yang belum memiliki smartphone dan laptop.

Zoom meeting merupakan media yang dapat digunakan secara langsung dengan siapapun sehingga sangat cocok digunakan untuk pembelajaran jarak jauh di tengah pandemi ini. Pemanfaatan media zoom ini akan sangat membantu guru dan siswa dalam proses belajar karena dapat berinteraksi dan berkomunikasi secara tatap muka walaupun di tempat yang berbeda.

Berdasarkan teori komunikasi pendidikan yang mengemukakan bahwa dalam proses pembelajaran tentunya diperlukan adanya proses komunikasi. Berbagai bentuk Komunikasi dapat terjadi dalam proses belajar yang apabila dilihat dari subjeknya maka komunikasi tersebut dapat meliputi komunikasi antar siswa dan komunikasi dalam ruang kelas antar guru dengan siswa. Teori ini sejalan dengan penelitian yang akan dilaksanakan yaitu untuk melihat bagaimana efektifitas penggunaan media zoom terhadap pembelajaran di masa pandemi Covid 19 ini. Adapun pengukuran dalam dalam penelitian ini adalah untuk mengetahui sejauh mana efektifitas penggunaan media zoom terhadap pembelajaran di masa pandemi Covid-19 di SDN 117 Leppangeng. Hasil penelitian ini tentunya diharapkan dapat membantu tenaga pendidik secara umum dan guru SDN 117 leppangeng khususnya dalam melaksanakan pembelajaran jarak jauh selama masa pandemi covid -19 .

\section{METODE}

Desain penelitian ini menggunakan pendekatan penelitian kualitatif. Cresweel mengungkapkan bahwa penelitian kualitatif merupakan suatu pendekatan atau penelusuran guna mengumpulkan informasi dan data dengan bantuan berbagai sumber kepustakaan seperti dokumen, buku, majalah, dan kisah sejarah. Cara pengambilan data kepustakaan tersebut melalui metode wawancara yang mendalam (deep interview) kepada 7 orang tenaga pendidik (guru) di SDN 
117 Leppangeng. Data yang diperoleh disajikan dalam bentuk narasi untuk memperoleh gambaran mengenai efektifitas dan kendala yang dihadapi dalam penggunaan media zoom.

Rancangan penelitian dibuat dalam beberapa tahapan yang meliputi : membuat beberapa pertanyaan kepada siswa, melakukan penyebaran materi pertanyaan secara online melalui media sosial seperti whatsapp, hasil atau jawaban dari wawancara tersebut kemudian dikumpulkan dan kemudian dianalisis.

Analisis data merupakan suatu proses sistematisi data yag diperoleh dari hasil penelitian seperti hasil wawancara, penelusuran (obesevasi) dan dokumentasi. Data penelitian tersebut kemudian dikelompokkan berdasarkan masing-masing kategori, menjabarkan unit-unit, melakukan sintesa, meyusun dan memilah data yang penting untuk disajikan serta membuat kesimpulan sehingga mudah dipahami oleh diri sendiri maupun orang lain yang membacanya (Sugiyono, 2011).

\section{HASIL DAN PEMBAHASAN}

Berdasarkan analisis data yang dilakukan, diperoleh hasil penelitian sebagai berikut :

Tabel 1. Persentase pendapat siswa terhadap efektifitas penggunaan zoom

\begin{tabular}{cc}
\hline Pendapat Siswa & Persentase \\
\hline Efektif & $40 \%$ \\
\hline Tidak Efektif & $60 \%$ \\
\hline
\end{tabular}

Hasil yang diperoleh dalam penelitian ini menunjukkan bahwa penggunaan aplikasi zoom meeting terhadap pembelajaran di sekolah dasar khususnya di SDN 117
Leppangeng Bone masih dikategorikan "kurang efektif". Faktor kendala terhadap kurang efektifnya pembelajaran jarak jauh melalui aplikasi zoom meeting, yaitu masih terdapatnya beberapa siswa yang belum memiliki fasilitas smartphone dan laptop yang dapat mengakses aplikasi tersebut, masih terdapat pula orang tua maupun guru belum menguasai cara mengoperasikan aplikasi zoom meeting, rendahhnya kualitas sinyal pada beberapa wilayah tempat tinggal siswa dan guru juga merupakan faktor kendala terhadap masih kurang efektifnya penggunaan aplikasi zoom bagi proses pembelajaran siswa. Selain terdapatnya kendala seperti yang telah dibahas sebelumnya, tidak sedikit pula yang mengapresiasi penggunaan penggunaan aplikasi zoom meeting, beberapa orang tua dan guru dalam wawancara yang dilakukan menyampaikan bahwa aplikasi zoom meeting dinilai sangat praktis dalam penggunaan. Salah satu keunggulan yang dipaparkan oleh orang tua adalah dikarenakan siswa dan guru melaksanakan proses pembelajaran melalui komunikasi secara langsung (via video confrence) dan tidak hanya melalui pembelajaran dengan materi tertulis. Proses komunikasi secara langsung (via apliasi) memudahkan siswa melakukan feedback termasuk bertanya apabila ada materi yang belum jelas dan belum dimengerti.

Pembelajaran melalui media zoom meeting dewasa ini telah menjadi salah satu solusi pembelajaran, meskipun dalam pelaksanaannya tidak semudah dengan apa yang dibayangkan. Salah satu responden penelitian, Asniati yang juga terdaftar sebagai salah satu tenaga pendidik (guru) di Sekolah Dasar Negeri (SDN) 117 Leppangen mengungkapkan bahwa dalam pembelajaran siswa pada kelas 2 SDN 117 Leppangeng telah menggunakan zoom meeting sebagai pengganti tatap muka ruang kelas. Lebih 
lanjut Asniati menambahkan bahwa dalam proses pembelajaran tersebut tidak semua peserta didik dalam kelasnya dapat mengakses aplikasi tersebut dengan berbagai alasan seperti media smartphone adalah milik orang tua mereka sehingga siswa hanya dapat menggunakan smartphone tersebut apabila orang tua mereka telah pulang dari bekerja. Selain itu, masih terdapat orang tua siswa yang masih terbilang kurang mengusai "gagap teknologi” sehingga tidak mengetahui cara mengoperasikan aplikasi. Guna mengatasi perihal-perihal kendala tersebut, Asniati juga menggunakan alternatif aplikasi pembelajaran daring lainnya seperti google doc, dengan mengirimkan tautan materi pembelajaran baik kedalam "Group Chat" maupun ke kontak pribadi orang tua siswa. Selain itu, aplikasi ini juga dapat membantu penilaian harian siswa karena pemberian nilai dapat langsung dimasukkan ke dalam form google.

Selain Asniati, salah satu Guru di SDN 117 Leppangeng juga mengungkapkan bahwa dalam pembelajaran online dia menggunakan berbagai macam aplikasi pembelajaran untuk menghindari rasa jenuh siswwa dalam melaksanakan pembelajaran di rumah. Dalam penilaiannya, aplikasi pembelajaran yang mendapat respon yang baik oleh siswa maupun orang tua mereka adalah aplikasi zoom meeting karena dengan aplikasi ini siswa dan guru dapat langsung bertatap muka, dan siswa dengan mudah mendapatkan penjelasan materi serta memberikan pertanyaan kepada guru apabila terdapat materi yang masih belum dipahami. Hal yang perlu diperhatikan oleh pihak sekolah dan guru adalah seyogyanya memberikan pelatihan kepada orang tua siswa tentang cara penggunaan aplikasi zoom ini agar dapat mengunakan aplikasi zoom meeting ini dengan baik dan benar.
Hasil dalam penelitian ini juga sejalan dengan pendapat Hartanto (2016) bahwa teknologi informasi dan telekomunikasi yang murah dan mudah akan mereduksi keterbatasan ruang dan waktu yang selama ini menjadi keterbatasa dalam dunia pendidikan. Konsekuensi penggunaan e-learning seperti yang saat ini dibangun dalam sistem pendidikan Indonesia adalah siswa dapat dengan mudah mengakses materi pembelajaran tanpa terbatas lagi dengan tempat dan waktu. E-Learning memudahkan siswa dalam mendapatkan materi pembelajaran dan membuka ruang diskusi dengan para pendidik di bidang yang diminati. Baik materi pembelajan sesuiai dengan kurikulum yang dilaksanakan maupun materi pembelajaran lainnya dapat dengan mudah diakses atau diperoleh dari berbagai sumber media din internet tanpa harus terkendala oleh ruang dan waktu. Kendala utama yang masih dialami negara kita adalah dengan masih perlunya pembangunan berbagai infrastuktur teknologi informasi dan pengkajian mengenai berbagai peraturan yang mendukung terhadap pengembangan elearning di Indonesia.

Di balik banyaknya kemudahan yang ditawarkan dari pembelajaran daring melalui internet, melalui penelitian ini masih ditemukan banyak kendala yang dihadapi oleh masyakat kita dalam menyesuaikan diri dengan situasi pembelajaran pada masa pandemi seperti saat ini. Baik dari hasil wawancara maupun melalui pengamatan langsung, informasi yang diperoleh masih menunjukkan bahwa pembelajaran melalui media internet khususnya pada SDN 117 Leppangeng dalam pemanfaatan aplikasi zoom meeting masih dalam kategori penilaian "kurang efektif". Untuk beberapa responden, baik siswa, guru maupun orang tua peserta didik masih menganggap bahwa pembelajaran 
tatap muka langsung dalam ruang kelas adalah proses belajar yang paling efektif. Kelebihan utama proses pembelajaran kelas yang tidak mampu digantikan oleh media internet adalah pembangunan karakter dan moral anak serta kemampuan bersosialisasi mereka.

Terhadap masih terdapatnya ketidakefektifan pembelajaran daring, Eva Maizarra Puspita Dewiyang yang merupakan seorang psikolog pendidikan dalam pendapatnya mengemukakan bahwa terdapat tiga reaksi individu saat diperhadapkan dalam situasi sulit yaitu menolak, tawar menawar dan menerima. Berkaitan dengan era New Normal yang saat ini dihadapi masyarakat, bahwa saat ini siswa lebih menyukai pembelajaran tatap muka ruang kelas karena mereka masih dalam tahap menolak karena harus kita akui bersama bahwa sistem pembelajaran daring ini masih tergolong baru serta memerlukan berbagai penyesuaian dalam pelaksanaannya.

\section{SIMPULAN DAN SARAN}

Simpulan

Penggunaan aplikasi zoom meeting di Sekolah Dasar Negeri (SDN) 117 Leppangeng Bone masih "kurang efektif". Faktor kurang efektifnya pembelajaran jarak jauh ini (zoom meeting) adalah dipengaruhi beberapa hal diantaranya masih ada beberapa siswa yang belum memiliki smartphone dan laptop, guru dan orang tua siswa belum memahami penggunaan apliaksi zoom meeting dengan baik, dan rendahnya kualitas sinyal pada lingkungan tempat tinggal siswa dan guru. Selain kendala di atas, melalui penelitian ini juga ditemukan informasi bahwa beberapa orang tua siswa dan guru menilai bahwa apliaksi zoom meeting masih menjadi pilihan solusi yang tepat untuk mengganti proses pembelajaran dalam ruang kelas. Aplikasi zoom meeting menawarkan keunggulan lebih dibandingkan dengan aplikasi pembelajaran lainnya yang sejenis karena siswa dan guru dapat melakukan komunikasi secara lisan dan tatap muka layaknya pembelajaran kelas.

Saran

Proses pembelajaran jarak jauh via internet yang dilaksanakan oleh siswa pada tingkat Sekolah Dasar khususnya pada SDN 117 Leppangeng sebaiknya dilakukan dengan tetap dibawah pengawasan orang tua dan guru. Kerjasama antara guru dan orang tua perlu senantiasa ditingkatkan agar proses pembelajaran ini menjadi lebih efektif dan dapat dimanfaatkan dengan baik oleh semua pihak. Pembelajaran jarak jauh juga harus senantiasa dikembangkan oleh guru untuk menyajikan metode pembelajaran yang menyenangkan dan lebih bervariasi bagi para siswa. Pembelajaran yang menyenangkan dan bervariasi bertujuan untuk menghindarkan rasa jenuh siswa dalam belajar.

Dalam upaya peningkatan ke-efektifitasan pembelajaran daring, kedepannya pihak guru dan sekolah diharapkan menerapkan sepuluh saran yang diberikan orang tua siswa dan para peserta didik diantaranya (1) bantuan kuota internet bagi siswa; (2) pengadaan WiFi di sekolah yang dapat dimanfaatkan siswa secara bergantian (3) membatasi materi pembelajaran dalam bentuk video berukuran berat; (4) Setiap materi dalam bentuk tertulis maupun dalam bentuk video menggunakan bahasa yang mudah dimengerti oleh peserta didik; (5) mendahulukan materi sebelum memberikan tugas; (6) soal yang bervariatif dan tidak terlalu sulit untuk dikerjakan oleh siswa; (7) pemberian cara kerja tugas kepada orang tua agar mudah membimbing anak mereka dalam belajar; (8) memberikan tugas sesuai dengan materi pelajaran yang telah dilewati; (9) senantiasa mengingatkan peserta didik atau orang tua peserta didik jika 
terdapat tugas yang diberikan; dan (10) jumlah tugas yang dibebankan kepada peserta didik tidak terlalu banyak.

Referensi

Gikas dan Grant, 2013. Mobile computing devices in higher education: Student

perspectives on learning with cellphones, smartphones \& social media. Iniemei and Higher Education, 19, 18-

26.

http://dx,doi.org/10.1016/j.ih educ.2013.06.002.

Hartanto, W. 2016. Penggunaan E- Learning sebagai Media Pembelajaran. Jurnal Pendidikan Ekonomi, 10(1), 1-18.

Sandiwarno, 2016. Perancangan Model ELearning Berbasis Collaborative Video Conference Leraning guna Mendapatkan Hasil Pembelajaran yang Efektif dan Efisien. Jurnal Ilmiah FIFO 8(2) 191. http ;//doi.org/10.22441/fifo.v812 .i314.

Silahuddin, 2015. Penerapan E- Learning dalam Inovasi Pendidikan. CIRCUIT,- Jurnal Ilmiah Pendidikan Teknik Elektro, 1 48-59. http;//doi.org/10.22373/crc.v 1i1.310.

Sugiyono, 2011. Metode Penelitian

Pendidikan

(Pendekatan
Kuantitatif Kaualitatif). Alfabeta. dan

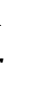

.

